\title{
Neoserial, serial premium czy post soap opera? W poszukiwaniu wyznaczników dla seriali nowej generacji
}

\author{
ARTUR BOROWIECKI \\ Katedra Mediów i Kultury Audiowizualnej \\ Instytut Kultury Współczesnej \\ Uniwersytet Łódzki
}

\begin{abstract}
Borowiecki Artur, Neoserial, serial premium czy post soap opera? W poszukiwaniu wyznaczników dla seriali nowej generacji [Neo series, premium series or post soap opera? In looking for characteristics of the new generation TV series]. "Images” vol. XXV, no. 34. Poznań 2019. Adam Mickiewicz University Press. Pp. 163-171. ISSN 1731-450X. DOI 10.14746/i.2019.34.11.

Modern television series are a product of quality television and thus significantly differ from the models that have been deeply rooted in serial culture since the very beginning of the media's existence. In the past, television formats were thematically subject to the requirements of television broadcast programming. They were characterized by five-act structures, with climaxes forced by television stations to occur before subsequent commercial breaks. At that time, the dominating category constituted series with an episodic structure closed within one episode. This resulted in the appearance of the currently widespread procedurals. Nonetheless, the three-act structure of sitcom plots dominates nowadays, in the post-network era. Another significant feature of the post soap is its narrative complexity (Mittell), which, in addition to formal procedures, often uses quotes, and autotematic references. The purpose of this article is to analyze the narrative complexity of new generation TV series, called "post soap". A new genre of TV series has been examined through the examples of a popular show: Ślepnąc od świateł (2018).
\end{abstract}

KEYwORDS: modern drama series, narrative complexity, quality serial, Post-Soap, heavily serialized

\section{Neoserial}

Podczas piątej edycji festiwalu scenarzystów ScripFiesta 2016 prowadząca zajęcia scenariuszowe Agnieszka Kruk[1] w części wykładu nawiązała do konstrukcji współczesnych seriali. Jednak przy próbie nazwania tychże produkcji, to znaczy wyróżnienia ich jako posiadających charakterystyczny typ struktury narracyjnej względem tradycyjnych form, prowadzącej trudno było sformułować konkretne określenie współczesnych seriali; ostatecznie zdefiniowała je jako te, „które mają fajną oglądalność”[2]. Nasuwa się pytanie czy współczesne seriale mają nazwę, która jest ich wyróżnikiem względem tradycyjnych seriali?[3]. Interesującym zagadnieniem jest to, w jakim stopniu masowo produkowane w ostatnich latach seriale odróżniają się od produkcji dominujących przed tak zwanym złotym okresem telewizji[4]. Czy można mówić o nowej jakości serialowych produkcji z charakterystycznymi cechami wyznaczającymi nowy paradygmat opowiadania?

[1] Agnieszka Kruk - scenarzystka i instruktorka scenariopisarstwa, organizatorka kursów, warsztatów i wydarzeń dla scenarzystów, jurorka w konkursach filmowych i scenariuszowych. [2] Jako przykłady neoseriali Kruk wymieniła Californication (2007-2014) oraz House of Cards (2013-2018) - <https://www.youtube.com/ watch?v=XrjJRrwoEfA\&t=27156s $>$ [dostęp: 1.05.2019].

[3] Pisząc „tradycyjne”, mam na myśli te, które nie mają cech złożonej narracyjności (termin będzie wyjaśniony w dalszej części artykułu). [4] Dokładnie trzeci złoty okres, którego początek wyznacza emisja serialu Rodzina Soprano w 1999 roku. Dwa poprzednie „złote okresy” telewizji to lata 1947-1961, oraz 1981-1994 (por. R.J. Thompson, Television's Second Golden Age: From Hill Street Blues to ER, New York 1997). 
164 VARIA

W kwestii pierwszej, dotyczącej nazwy dla nowo produkowanych seriali, trudno znaleźć jakiekolwiek określenie w języku potocznym. W czasopismach branżowych (filmowo-serialowych) używa się sporadycznie nazwy „neoserial”, wymiennie stosowanej z terminem „serial nowej generacji”. Trudno jednak ustalić cezurę powyższych określeń, jak i jednoznacznie definiować powyższe terminy, gdyż funkcjonują jako „rozdzielniki” seriali nowego milenium od produkcji powstałych wcześniej.

Akademicy od lat osiemdziesiątych mówią o „serialach lepszej jakości”, nazywając je „dramatami jakościowymi” (quality drama) jako produkcjach, które są wytworem tak zwanej telewizji jakościowej (quality television). W Polsce w nieco żartobliwy sposób Mirosław Filiciak nazywa je post soap operami, wskazując, iż, podobnie jak opery mydlane, współczesne produkcje mają wątki, które są rozciągnięte[5] na czas trwania całej emisji serialu[6]. W środowisku producentów filmowych czy stacji telewizyjnych[7] nazywa się je „serialami premium”, wskazując, iż produkcje emitowane w czasie

[5] Arkadiusz Lewicki nazywa je „wątkami przechodnimi" (por. A. Lewicki, Od House'a do Shreka. Seryjność w kulturze popularnej, Wrocław 2011, s. 36).

[6] Por. M. Filiciak, TV czy nie-TV?, [w:] Post-Soap: nowa generacja seriali telewizyjnych a polska widownia, red. M. Filiciak, B. Giza, Warszawa 2011.

[7] Dla przykładu takich nazw używają stacje typu Canal+ czy Showmax.

[8] Termin został użyty przez Jasona Mittella $\mathrm{w}$ artykule Narrative Complexity in Contemporary American Television w czasopiśmie filmowym „The Velvet Light Trap”, 2006 nr 58. W wydanym w 2015 podręczniku Complex TV. The Poetics of television storytelling wprowadza termin złożonej telewizji (Complex TV) używany często wymiennie z terminem złożona narracyjność.

[9] Por. J. Mittell, Złożoność narracyjna we współczesnej telewizji amerykańskiej, tłum. D. Kuźma, [w:] Zmierzch telewizji? Przemiany medium. Antologia, wyb. i red. T. Bielak, M. Filiciak,

G. Ptaszek, Warszawa 2011, s. 176.

[10] J. Mittell, Narrative Complexity..., s. 32.

[11] Por. idem, Złożoność narracyjna..., s. 166-171. największej oglądalności wyróżnia lepsza jakość niż seriale prezentowane w innych godzinach emisji.

Na koniec odwołam się do terminologii Jasona Mittella, jako teoretyka, który, jak do tej pory, najpełniej omawia seriale nowej generacji, zaliczając większość $\mathrm{z}$ nich do produkcji złożonych narracyjne (narrative complexity) [8]. Początków owej „złożoności” upatruje w serialach wyprodukowanych na przełomie lat osiemdziesiątych i dziewięćdziesiątych minionego stulecia. Jako tytuły nowatorskich seriali wymienia zarówno sitcomy: Kroniki Seinfelda (Seinfeld, 1989-1998), Bogaci bankruci (Arrested Development, 2003-2006, wznowiony 2013), ale przede wszystkim seriale dramatyczne: Miasteczko Twin Peaks (Twin Peaks, 1990-1991, wznowienie 2017) Prezydencki poker (The West Wing, 1999-2006), Z Archiwum X (X-files, 19932002, wznowienie 2016), Rodzina Soprano (The Sopranos, 1999-2007). Badacz nie tylko wprowadza nazwę dla współczesnych seriali, lecz jednocześnie wskazuje na zespół czynników, które są wyróżnikami nowego paradygmatu opowiadania serialowego[9]. W ogólnym ujęciu złożona narracyjność, jak twierdzi Mittell, „polega na przedefiniowaniu form epizodycznych pod wpływem narracji seryjnej - niekoniecznie na całkowitym ich połączeniu, lecz na przeniesieniu środka ciężkości”[10]. Wśród innych formalnych wyznaczników narracyjnej złożoności Mittell wymienia między innymi: proliferację linii fabularnych wzajemnie na siebie wpływających, strategie narracyjne kształtowane poprzez narracyjne efekty specjalne (narrative special effect) i wielopoziomowe struktury dramaturgiczne[11]. Odnosząc się do powyższych wyznaczników nowego stylu opowiadania, należy zauważyć, że jako nadrzędną zmianę w serialach złożonych narracyjnie Mittell traktuje inny rodzaj hierarchiczność poszczególnych wątków. O ile seriale epizodyczne charakteryzuje dominująca rola wątków zamkniętych (self-contained), to współcześnie twórcy najczęściej korzystają z ciągłości wątków (continuing) dotyczących całego sezonu. Filmoznawca swoje obserwacje odnosi do amerykańskich 
produkcji, ale niewątpliwie taki typ konstrukcji odnajdujemy również w europejskim przemyśle medialnym. Wymienię kilka najbardziej znanych produkcji: Downton Abbey (Downton Abbey, 2010-2015), Broadchurch (Broadchurch, 2013-2017), Forbrydelsen (Forbrydelsen, 2007), Shameless (Shameless, 2004-2013), Most nad Sundem (Broen, 2011-2018).

Potencjał, zarówno artystyczny, jak i niewątpliwe finansowy, tkwiący w produkcjach neoseriali dostrzegli również polscy twórcy. Nielicznym spośród nich udało się z powodzeniem skorzystać z nowatorskich form narracji serialowej, przełamując utrwaloną w masowej świadomości widzów tradycyjną konwencję opowiadania. Na krajowym rynku powstały takie produkcje jak Glina (2003-2008), Pitbull (2005-2008), Ekipa (2007). W kolejnych latach rodzimi producenci skorzystali z zachodnich neoseriali, kupując formaty i adaptując nowatorskie produkcje na polski rynek (Bez tajemnic, 2011-2013, Pakt, 2015-2016, Krew $z$ krwi, 2012-2015), tym samym popularyzując nowy paradygmat serialowego opowiadania wśród polskiej widowni. W konsekwencji stacje telewizyjne, zwłaszcza kablowe, zaczęły produkować coraz więcej seriali, wśród których nie tylko treści, ale także struktura fabularna uległa znacznym modyfikacjom względem starego typu opowiadania, jak choćby w serialach: Wataha (2014), Kruk. Szepty stychać po zmroku (2018-) czy Ślepnąc od świateł (2018). Na przykładzie tego ostatniego, w którym twórcy skorzystali z pełnej palety środków i zabiegów formalnych zaliczanych w poczet złożonej narracyjności, zostaną omówione poszczególne wyróżniki współczesnych seriali.

\section{Kształtowanie serialowej złożoności}

Pomimo iż, jak wskazuje Mittell, złożona narracyjność ukształtowała się na przełomie lat osiemdziesiątych i dziewięćdziesiątych, proces ewolucji form serialowych został zapoczątkowany już w latach siedemdziesiątych, kiedy podjęto pierwsze próby „przełamania” epizodyczności serialowej poprzez wprowadzanie wątków kontynuowanych. O tego typy ekspery- mencie można mówić w przypadku produkcji powstałej w studiu MTM Production - The Mary Tylor Moor Show (1970-1977). Twórcy skorzystali z tak zwanego łuku przemiany bohatera (character arc), eksponując wewnętrzną transformację tytułowej postaci Mary Richards. Wraz z emisją kolejnych odcinków zmieniały się cechy jej charakteru, eksponowane na tle przemian kulturowych Ameryki lat siedemdziesiątych[12]. Pomimo że w powyższym przykładzie trudno mówić o wątku kontynuowanym, to jednak przełamano nienaruszalną zasadę niezmienności charakterów postaci serialowych. W kolejnych latach twórcy z tej samej wytwórni dokonali wręcz rewolucyjnych zmian w strukturze fabularnej tworzonych seriali. W produkcjach Posterunek przy Hill Street (Hill Street Blues, 1981-1987) oraz St. Elsewhere (St. Elsewhere, 1982-1988) poszczególne wątki nie miały zamkniętych przebiegów dramaturgicznych, w ujęciu jednego odcinka tylko "rozciągano" je na dwa, czasami trzy kolejne epizody serialowe. Wpływało to na nawarstwianie się kolejnych fabuł, tak iż czasami widz musiał śledzić znacznie więcej niż cztery wątki, będące w tamtym okresie ustandaryzowaną liczbą przypadającą na jeden odcinek[13]. Zmiany były na tyle innowacyjne względem starego sposobu konstruowania seriali, że, jak wspomniano wcześniej, grupa akademików[14], analizując produkcje powstałe w MTM Production, wyróżniła zespół cech charakterystycznych dla seriali „lepszej jakości”. Dramaty jakościowe opisywano jako te, których twórcy między innymi: przełamywali tradycyjne zasady kompozycji, korzystali z wątków kontynuowanych zamiast epizodycznych, mieszali gatunki, wprowadzali do seriali większą liczbą wątków, czy w końcu podejmowali kontrowersyjne, wcześniej niepo-

[12] Por. J. Feuer, Narrative form in American Network Television, [w:] High Theory/Low Culture, ed. C. MacCabe, Manchester 1986, s. 112.

[13] W anglojęzycznej literaturze występuje pod nazwami „story A, B, C, D”.

[14] Mam tu na myśli badania prowadzone przez: Jane Feuer, Roberta Thompsona i Susan Boyd-Bowman. 
ruszane $\mathrm{w}$ telewizji tematy[15]. $\mathrm{Na}$ podstawie poczynionych obserwacji Robert Thompson postulował, by w przypadku seriali jakościowych utworzyć nowy gatunek telewizyjny celem wyróżniania ich spośród innych produkcji telewizyjnych. Nic takiego jednak nie nastąiło, co w jakiś sposób jest do dziś problematyczną kwestią, gdyż nadal większość produkcji serialowych funkcjonuje pod zbiorczą nazwą „serial”[16].

Kolejnym znaczacym etapem dla rozwoju form serialowych była emisja jednej z najoryginalniejszych produkcji telewizyjnych lat dziewięćdziesiątych - serialu Miasteczko Twin Peaks. Filmoznawczyni Kristin Thompson wymienia go jako jedną z dwóch produkcji[17] przenoszących na mały ekran elementy kina artystycznego[18]. David Lynch skorzystał z postmodernistycznych chwytów udziwniających jak: „żonglerka” różnego rodzaju motywami, nietypowe zwroty akcji czy zaburzenia temporalności opowiadania. W przypadku tego ostatniego należy zauważyć, iż zakłócenia linearności opowiadania pojawiały się w serialach od samego początku ich istnienia, jednak używane były jako „narracje wyjaśniające”. W serialowym miasteczku Twin Peaks i wszelkich późniejszych neoserialach, jak twierdzi Mittell, wprowadzone zakłócenia do chronologii fabularnej mają na celu wywołanie u widza chwi-

[15] Por. R.J. Thompson, op.cit., s. 13-16.

[16] Oczywiście istnieją podgatunki, jak opera mydlana, sitcom czy miniserial, jednak zarówno Ślepnąc od świateł, jak i inne produkcje, choćby dla przykładu polskie seriale Czterdziestolatek czy Stawka większa niż życie, nazywa się tak samo, czyli „serial”. Odrębną kwestią pozostaje skostniały podział na seriale i serie. Jednak z uwagi na spopularyzowanie obecnie wątków kontynuowanych ten rozdzielnik staje się nieaktualny. [17] Drugi to brytyjski miniserial Śpiewający detektyw (The Singing Detective, 1986).

[18] Por. K. Thompson, Storytelling in Film and Television, Cambridge 2003, s. 132.

[19] Por. J. Mittell, Złożoność narracyjna..., s. 167.

[20] Ibidem, s. 169.

[21] Produkcja wykonawcza została zlecona firmie House Media Company. lowej dezinformacji[19]. Według filmoznawcy $\mathrm{w}$ produkcjach, których twórcy umiejętnie korzystają z tego typu rozwiązań formalnych, podziwiamy fabuły na równi ze sjużetem, przez co oglądając kolejne odcinki neoseriali zadajemy sobie pytanie: "nie co się stanie, ale jak oni to zrobili?"'[20]. Wpływają na to współcześnie stosowane zabiegi kompozycyjne (nieoczekiwane twisty, flashbacki, futurospekcje, elipsy czasowe), poprzez które widzowie wręcz są „zmuszani” do przeinterpretowania tego, co już widzieli wcześniej.

Oczywiście rozwój form serialowych nie zatrzymał się w latach dziewięćdziesiątych, jednak filmy powstałe w studiu MTM Production oraz Miasteczko Twin Peaks "przetarły” twórcom drogę dla dalszych eksperymentów i rozwijania formuły serialowej. Doskonałym przykładem połączenia zarówno tego, co akademicy w latach osiemdziesiątych nazwali „telewizją jakościową”, jak i mittellowskiej „złożonej narracyjności", jest polski serial wyprodukowany przez HBO [21] Ślepnąc od świateł. W produkcji skorzystano z środków stylistycznych, które są wyznacznikami nowego paradygmatu opowiadania. W dalszej części artykułu są one wymienione wraz z konkretnymi odniesieniami do fragmentów serialu.

\section{Ślepnac od światet jako neoserial}

Serial Ślepnac od świateł powstał na podstawie powieści Jakuba Żulczyka pod tym samym tytułem. W serialu obserwujemy siedem dni z życia warszawskiego dilera narkotyków Jakuba Niteckiego (Kamil Nożyński), które są eksponowane w ciągu ośmiu odcinków serialowych. Bohater podejmuje decyzję o wyjeździe do Argentyny, argumentując to koniecznością „wakacji”, na których, jak sam podkreśla, nigdy nie był. Potencjalny wyjazd Kuby do Ameryki Południowej jest metaforą zerwania $\mathrm{z}$ dotychczasowym gangsterskim stylem życia, co, jak się okazuje, w świecie przestępczości zorganizowanej nie jest możliwe. Jego plany komplikują się, gdy dostaje na przechowanie torbę wypełnioną narkotykami i pieniędzmi, której właścicielem jest, kończący odbywanie 
wyroku, gangster „Dario” (Jan Frycz). Realizacja marzenia o „wakacjach” z czasem przeradza się w walkę o przetrwanie, gdy zaczyna na niego polować nie tylko „Dario”, ale również jego szef Jacek (Robert Więckiewicz), media i policja.

Twórcy serialowi, przedstawiając historię dilera narkotykowego, nie omijają tematów kontrowersyjnych. W fabule serialowej nawiązują do licznych problemów społecznych związanych głównie z narkomanią. Jednak nie doświadczymy tu obrazowania nizin społecznych tylko ludzi bogatych, dla których narkotyki są jedną z form rozrywki, jak choćby kobietę z wyższych sfer (Ewa Skibińska), znanego polityka (Zbigniew Suszyński) czy celebrytę (Cezary Pazura) prowadzącego popularne programy telewizyjne. Twórcy zaglądają za kulisy polskiego show-biznesu muzycznego, pokazując życie gwiazd sceny hiphopowej, które między kolejnymi ujęciami swoich teledysków „dopalają się" mocnymi narkotykami. Epizodycznie twórcy dokonują wiwisekcji polskiego wymiaru sprawiedliwości, w którym nie tyle liczy się sama „idea prawa”, co zajmowanie się medialnymi sprawami celem uzyskania poklasku społecznego. Obrazowane przez Żulczyka postacie przywodzą na myśl znane osoby ze świata mediów i polityki, których życie mogło być pierwowzorem danych sytuacji serialowych, co przekłada się na zwiększony realizm poszczególnych sekwencji[22]. Oczywiście o ile tego typu problemy są od lat eksponowane w filmach fabularnych, to należy zauważyć, iż pokazywanie kontrowersyjnych treści na „małym ekranie" jest traktowane jako jeden $\mathrm{z}$ wyznaczników neoserialowych.

Jak zauważa Zuzanna Lewandowska, dynamiczny rozwój seriali przejawia się nie tylko $\mathrm{w}$ ujęciu tematycznym, lecz również w zmianie ich konstrukcji[23]. W przypadku Ślepnąc od świateł mamy do czynienia $\mathrm{z}$ tak zwaną mocną serializacją (heavily serialized). W ramach pojedynczych odcinków twórcy nie korzystają $\mathrm{z}$ wątków epizodycznych, o strukturze zamkniętej, co potwierdza Mittellowską uwagę o przesunięciu akcentu $\mathrm{z}$ epizodyczności na rzecz kontynuacji fabularnej w ujęciu całego sezonu serialowego. Narracja filmowa oparta jest na głównej osi dramaturgicznej oraz licznie uzupełniających ją wątkach kontynuowanych na przestrzeni całego sezonu, przez co można wskazać na występowanie wielopoziomowej dramaturgii w neoserialch. W Ślepnac od świateł główna linia fabularna (story arc) realizowana jest w oparciu o strukturę klasycznego filmu fabularnego $\mathrm{z}$ wyrazistym podziałem na trzy akty, których zakończenia wyznaczają punkty zwrotne[24]. Akt pierwszy w analizowanym serialu przebiega na zasadzie ekspozycji postaci, wyznaczenia celu dla bohatera (wyjazd do Ameryki Południowej) oraz rozpoczęcia wątków wspomagających (wyjście Daria z więzienia, zdobycie torby z narkotykami, długi właściciela nocnego klubu), które są kluczowe dla całego toku opowiadania. Punktem katalizującym (zakłócającym codzienną egzystencję bohatera) jest przejęcie przez kolegów Jakuba torby wypełnionej narkotykami (epizod 1), która należy do gangstera Daria. Pierwszym punktem zwrotnym jest podjęcie decyzji przez Jakuba (epizod 2), gdy zgadza się przechować torbę przez trzy dni. Wraz z rozwojem akcji do fabuły wprowadzane są kolejne przeciwności o progresywnym natężeniu, z którymi zmaga się główny bohater (półświatek warszawski, szef klubu, policja). Zwieńczeniem kłopotów jest punkt zwrotny kończący drugi akt, gdy główny bohater po wyjściu z aresztu odkrywa, iż torba z narkotykami i pieniędzmi została skradziona, przez co traci zaufanie swojego szefa Jacka (Robert Więckiewicz). Zaistniałe wydarzenia komplikują życie Jakuba na tyle, iż próba wyjazdu do Argentyny zamienia się w desperacką walkę o przeżycie. Pomimo pozornego rozwiązania w trzecim akcie, gdy Kubie udaje

[22] Scenarzysta filmu Jakub Żulczyk przez wiele lat pracował jako dziennikarz.

[23] Z. Lewandowska, Złożoność współczesnego serialu telewizyjnego na przykładzie Breaking Bad Vince'a Giligana, „Images” 2015, vol. XVI, nr 25, s. 44 .

[24] Struktura filmowa zgodna z paradygmatem Syda Fielda (por. S. Field, Screenplay Foundations of Screenwriting, New York 2005). 
się uniknąć ponownego aresztowania, jego szef Jacek zostaje zabity, a marzenie o wyjeździe jest bliskie realizacji, odbiera telefon od Daria. Ten szantażuje go, że dokona egzekucji jego rodziny, jeśli nie będzie dla niego pracował. Pomimo domknięcia wątków pobocznych i pozornego zwycięstwa bohatera główny wątek (zmiana stylu życia) zostaje zawieszony (zastosowanie cliffhangera). Tym samym twórcy z jednej strony stosują narrację zamkniętą (poszczególne linie dramaturgiczne zostają rozwiązane), jednak kolejna przeszkoda na drodze do realizacji głównego celu bohatera jest „furtką” do napisania scenariusza następnego sezonu. Jest to regularnie używany zabieg dramaturgiczny przy produkcjach, w których serial limitowany (jak w przypadku Ślepnac od świateł) może być potencjalnie kontynuowany.

Celem doprecyzowania kwestii przedefiniowania struktur narracyjnych $z$ epizodycznych w ciągłe warto odnieść się do badań poczynionych przez filmoznawcę Michaela Z. Newmana. O ile Mittell mówi o ukształtowanych wątkach kontynuowanych, jednocześnie zaznaczając występowanie odcinkowej proliferacji linii narracyjnych, to Newman wskazuje na koherentność wielowątkowych narracji. Pomimo iż wprowadzane do serialu linie fabularne $\mathrm{z}$ początku mogą wydawać się niepowiązane z główną osią dramatyczną, to pod koniec danego sezonu czy nawet całej serii, poszczególne linie fabularne „zmierzają do narracyjnej jedności i spójności" [25]. Mamy do czynienia z sytuacją, w której trudno mówić o epizodyczności (jak w serialach tradycyjnych), tylko korelacji wątków pobocznych, czy wręcz o ich podrzędnej funkcji względem głównej osi narracji. „Wi-

[25] Por. M.Z. Newman, From beats to arcs: Toward a poetics of television narrative, "The Velvet Light Trap: A Critical Journal of Film and Television" 2006, nr 58, s. 25.

[26] J. Feuer, HBO i pojęcie telewizji jakościowej, tłum. D. Kuźma, [w:] Zmierzch telewizji? Przemiany medium. Antologia, wyb. i red. T. Bielak, M. Filiciak, G. Ptaszek, Warszawa 2011, s. 118.

[27] M.Z. Newman, op.cit., s. 25.

[28] Ibidem, s. 25. zualnie" wyjaśnia to Jane Feuer, wskazując, że wątki we współczesnych serialach są „ze sobą zestawiane i przeplatają się wzajemnie, zestrajając w quasi-muzycznym stylu" [26]. W Ślepnąc od światet praktycznie w każdym odcinku scenarzyści rozpoczynają nowe fabuły, które z czasem zostają skorelowane z główną linią dramaturgiczną. Wśród takowych wątków możemy wymienić między innymi: „Związek Kuby z Paziną”, „Wypadek drogowy celebryty”, "Skorumpowany policjant”, „Śledztwo w sprawie Kuby”, „Wesele córki Jacka”. Wszystkie wymienione wątki (jak i inne) są sukcesywnie rozwijane w kolejnych odcinkach, jednak nie w każdym muszą zaistnieć. Pomimo ich początkowej pozornej „niezależności” i odseparowania od głównej linii akcji „zmierzają w kierunku narracyjnej jedności i koherencyjności” [27], tworząc pod koniec serialu „pojedynczy wzór dramatycznego rozwiązania"[28]. Przykładem może być z pozoru epizodyczny wątek „posła narkomana”, który można analizować na poziomie odcinka, jak i całego sezonu. Fabuła w czwartym odcinku ma typowo epizodyczny przebieg chrakteryzujący się „samodzielną” strukturą wpisaną w ramy jednego odcinka. Poseł pod wpływem narkotyków zakupionych u Jakuba wpada w szał w pokoju hotelowym. Sprawą zajmuje się Kuba, który przy pomocy recepcjonisty i przyjaciółki Ewy rozwiązuje problem z politykiem. Rozpatrując ten wątek w ramach całego sezonu, należy przeanalizować trzy odcinki. Ekspozycja osoby posła następuje w pierwszym epizodzie, gdy zaopatruje się w narkotyki u Kuby. Główne wydarzenia związane z jego osobą mają miejsce w czwartym odcinku i incydencie hotelowym, natomiast ścisła korelacja z wątkiem głównym następuje w piątym odcinku. Kuba ścigany przez policjantów szantażuje telefonicznie posła, który ma skorzystać ze swoich konotacji, by diler nie został aresztowany, co też poseł niechętnie czyni. Tym samym pozornie epizodyczne wydarzenia stają się elementem składowym serialowej makro pozycji dramaturgicznej.

Kolejnym wyznacznikiem neoseriali jest stosowanie nietypowych połączeń stylistycz- 
nych czy wtrąceń, które przełamują powtarzalność tej samej konwencji formuły opowiadania. O ile w serialach tradycyjnych zauważalny jest minimalizm w odautorskiej interpretacji, wręcz zbliżanie się do kina stylu zerowego, o tyle we współczesnych produkcjach serialowych twórcy korzystają z zabiegów kompozycyjnych nazywanych przez Mittella „barokowymi udziwnieniami”. W Ślepnąc od świateł jednym z takich elementów „przełamujących” tradycyjną konwencję opowiadania jest upodabnianie fragmentów serialu do wideoklipów muzycznych. Konwencję teledysku odnajdziemy dla przykładu w sekwencji przyjęcia w domu celebryty (epizod 3), porcjowanie narkotyków przez Jakuba (epizod 1), szykujący się do „pracy” Kuba (epizod 2), sekwencji klubowej (epizod 1), przebitki na tańczące postacie w rytm utworu „Nienawiść” grupy Myslovitz (epizod 6), czy wręcz wplecenie fragmentu teledysku nagrywanego przez rapera „Pioruna” (w którego wcielił się reżyser filmu Krzysztof Skonieczny) w drugim epizodzie.

Powyżej opisane zabiegi stylistyczne czy eksponowanie kontrowersyjnych treści to jednak elementy, które pojawiały się w serialach jakościowych już od lat osiemdziesiątych. By w pełni zrozumieć neoserialową złożoność, należy rozpatrzyć środki formalne nazywane przez Jasona Mittella narracyjnymi efektami specjalnymi (narrative special effect). Znaczenie terminu nie jest przez autora doprecyzowane, służy jedynie podkreśleniu złożoności zabiegów kompozycyjnych, poprzez które scenarzyści przełamują dotychczas stosowane schematy narracyjne[29]. Wpływają na to umiejętnie zastosowane chwyty dramaturgiczne zaburzające linearność opowiadania (retrospekcji, futurospekcji, subiektywizacje, twisty serialowe itd.). Zakłócenia linearności opowiadania wprowadzone są „bez żadnych scen czy sygnałów oddzielających je od rzeczywistości” [30] celem dezorientacji widza. Mieke Bal używa określenia „achronii”, czyli niemożliwej do określenia fabularnej płaszczyzny czasowej[31]. Stosując tego typu zabiegi o różnym natężeniu, twórcy upodabniają neoseriale do filmów zaliczanych w poczet tak zwa- nych mind-game films, co przywodzi na myśl postmodernistyczne „zabawy z kinem”.

W Ślepnac od świateł linearność opowiadania jest zakłócona przez kilka typowych dopowiedzeń fabularnych wynikających bezpośrednio z kontekstu sceny poprzedzającej ich wprowadzenie (jak choćby tego, w jaki sposób Kuba poznał swojego szefa Jacka). Oprócz nich twórcy stosują retrospekcje "dezinformujące”. $\mathrm{Z}$ tego typu przypadkiem mamy do czynienia w sekwencji otwierającej (cold open) trzeci odcinek, gdy dowiadujemy się, jak niebieska torba $\mathrm{z}$ pieniędzmi i narkotykami znalazła się w posiadaniu gangstera Sikora. Wydarzenia są częścią głównego wątku serialowego i ich pokazanie jest niezbędne do zrozumienia historii serialowej, jednak sposób wprowadzenia sekwencji retrospektywnej „bez obawy przed chwilową dezorientacją widza" [32] jest chwytem dramaturgicznym stricte neoserialowym. W każdym z odcinków w wydarzenia fabularne wkomponowane są wizje Kuby metaforyzujące ciemną i jasną stronę jego osobowości. Twórcy zakłócają linearność opowiadania już pierwszą sceną, gdy obrazują oceaniczną plażę. Motyw plaży jest przywoływany wielokrotnie, jako fantazje głównego bohater. Poszczególne sceny czy to w wizjach, czy snach są transponowane niechronologicznie, zawierając elementy scenograficzne, które zaistnieją dopiero w dalszych częściach historii. Dla przykładu w epizodzie pierwszym główny bohater doświadcza wizji pomostu, na którym leży torba, a ta dopiero pojawia się w życiu Kuby, w dalszej części odcinka, stając się źródłem jego kłopotów. Regularnie w strukturę fabularną „wplatane” są mentalne obrazy, gdy Kuba, czy to zamyślony, czy w snach (jak można domniemywać) „odwiedza" czasami jako dziecko, innym razem jako dorosły, wymarłe miasteczko, gdzie spotyka rodziców przypominających włóczęgów, $\mathrm{Da}$ -

[29] Por. J. Mittell, Złożoność narracyjna..., s. 169.

[30] Ibidem, s. 172.

[31] Por. M. Bal, Narratologia. Wprowadzenie do teorii narracji, przekł. zesp. pod red. E. Kraskowskiej i E. Rajewskiej, Kraków 2013, s. 99.

[32] J. Mittell, Złożoność narracyjna..., s. 172. 
170 VARIA

ria jako duchownego. Fragmentarycznie Kuba w wizjach wyobraża sobie apokalipsę Warszawy, gdy na ekranie widzimy, jak kolejne fale zalewają stolicę. Kadry z katastrofy uzupełniają słowa pozadiegetycznej „modlitwy” głównego bohatera o zatonięcie Warszawy wraz z jej mieszkańcami i nim samym. Czasami subiektywizacje „wkraczają” do rzeczywistego świata, stając się omamami zmąconego narkotykami umysłu Kuby. Sytuacja ma miejsce w siódmym epizodzie, gdy diler, jadąc samochodem, widzi na miejscu pasażera zamordowanego kolege Sikora, który prorokuje $\mathrm{w}$ temacie przyszłości Kuby. Subiektywizacje wprowadzane są bez wyraźnych sygnałów zapowiadających ich pojawienie. Stanowią nie tyle element „dopowiedzenia”, uzupełnienia zastosowanych elips fabularnych, co uzupełniają metaforyczną przestrzeń w serialowej diegezie. Tego typu wtrącenia zgodnie z twierdzeniem Mittella pełnią również „funkcje pogłębiającą rys psychologiczny bohatera" [33]. Jakub przedstawiony jest jako introwertyk, minimalista słowny. Bez względu na to, czy ukazane są jego relacje zawodowe, czy związki towarzyskie z kobietami, emocje pozostają jego sekretem. Poprzez subiektywizacje mentalne scenarzyści „odkrywają” wnętrze bohatera, wręcz filmując stan jego umysłu.

\section{Podsumowanie}

Czy można w przypadku neoseriali dokonać ich jednoznacznej klasyfikacji na podstawie konstrukcji dramaturgicznej lub szeregu rozpoznawalnych cech formalnych? Niewątpliwie powszechnie już eksploatowana formuła fabuł

[33] Ibidem.

[34] Należy wspomnieć, że jednym z wyróżników neoseriali jest dominująca rola scenarzystów $\mathrm{w}$ procesie powstawania seriali, $\mathrm{w}$ przeciwieństwie do filmów fabularnych, które zawsze są kojarzone z reżyserem filmu.

[35] J. Bucknall-Hołyńska: Czy wspótczesne seriale spetniają kryteria kultury wysokiej?, <https:// teologiapolityczna.pl/justyna-bucknall-holynska-czy-wspolczesne-seriale-spelniaja-kryteria-kultury-wysokiej-tpct-46-> [dostęp: 1.05.2019]. kontynuowanych w miejsce stricte epizodycznych odróżnia współczesne produkcje serialowe od tradycyjnych. O ile w latach dziewięćdziesiątych kontynuowane schematy fabularne występowały w nielicznych serialach to obecnie ich stosowanie jest stałą praktyką twórczą. Jednak podczas analizy neoseriali zauważalne są nie tylko zmiany w makrostrukturach narracyjnych, ale również stosowanie wewnątrz odcinkowych strategii dyskursywnych będących wariacjami względem tradycyjnych reguł opowiadania. Mam tu na myśli wspomniane zaburzenia w chronologii opowiadania, nieoczekiwane zwroty fabularne, czy stosowanie chwytów dramaturgicznych, które z powodzeniem od lat są wykorzystywane przez twórców „dużego ekranu”. Tego typu strategii dyskursywnych zaczęto masowo używać w serialach po premierze Rodziny Soprano w 1999 roku. Produkcja nie tylko uzyskała pozytywne opinie u krytyków, ale również okazała się sukcesem komercyjnym. W wyniku tego stacje telewizyjne zaczęły produkować seriale, w których pozwolono scenarzystom [34] na większą swobodę twórczą, tym samym upowszechniając nowy paradygmat opowiadania serialowego w popkulturze. Należy zaznaczyć rodzaj procesualności w kształtowaniu nowego paradygmatu opowiadania, który podlega licznym modyfikacjom i eksperymentom (np. użycie solilokwium $\mathrm{w}$ House of Cards [House of Cards, 2013-2018], zastosowanie narracji pryzmatycznej w The Affair [The Affair, 2014- ] narracja prowadzona w kilku płaszczyznach czasowych w Westworld [Westworld, 2016- ]. Jednak zespół reguł - nazwijmy je „wyjściowymi” - które zostały omówione na przykładzie Ślepnac od świateł, pozostaje niezmienny dla nowo ukształtowanego stylu opowiadania w neoserialch. Oczywiście nie we wszystkich współczesnych produkcjach twórcy korzystają z wyznaczników nowego paradygmatu. Niektóre seriale zalicza się do tak zwanej telewizji śmieciowej (trash tv)[35], wskazując na nieumiejętne stosowanie środków złożonej narracyjności czy korzystanie z tradycyjnej skostniałej formuły opowiadania. 
Niewątpliwie w Ślepnąc od świateł obserwujemy skumulowanie nowych środków wyrazu, przy jednoczesnym niepopadaniu w rodzaj „zawirowań narracyjnych". Czy można to w jakiś sposób zmierzyć? Prawdopodobnie najlepiej odwołać się do opinii krytyków, zaliczających Ślepnac od świateł do najlepszej produkcji 2018 roku. Pozytywne opinie recenzentów podzielają widzowie, którzy przydzielają serialowi wysokie noty na licznych portalach internetowych[36]. Stacja HBO udostępniła serial amerykańskiej widowni. Magazyn „Variety” umieścił Ślepnac od świateł na liście najciekawszych tegorocznych seriali wyprodukowanych poza Stanami Zjednoczonymi, co przy setkach powstałych produkcji jest niewątpliwie nobilitującym wyróżnikiem.

\section{B I B L I O G R A F I A}

Bal M., Narratologia. Wprowadzenie do teorii narracji, przekł. zesp. pod red. E. Kraskowskiej i E. Rajewskiej, Kraków 2013

Bucknall-Hołyńska J., Czy współczesne seriale spetniaja kryteria kultury wysokiej?, „Teologia Polityczna”, $<$ https://teologiapolityczna.pl/justyna-bucknall-holynska-czy-wspolczesne-seriale-spelniaja-kryteria-kultury-wysokiej-tpct-46-> [dostęp: 3.01.2018].

Feuer J., HBO i pojęcie telewizji jakościowej, tłum. D. Kuźma, [w:] Zmierzch telewizji? Przemiany medium. Antologia, wyb. i red. T. Bielak, M. Filiciak, G. Ptaszek, Warszawa 2011
Feuer J., Narrative form in American Network Television, [w:] High Theory/Low Culture, red. C. MacCabe, Manchester 1986

Field S., Screenplay Foundations of Screenwriting, New York 2005

Filiciak M., TV czy nie-TV?, [w:] Post-Soap: nowa generacja seriali telewizyjnych a polska widownia, red. M. Filiciak, B. Giza, Warszawa 2011

Lewandowska Z., Złożoność współczesnego serialu telewizyjnego na przykładzie Breaking Bad Vince’a Giligana, „Images” 2015, nr 25, s. 44.

Lewicki A., Od House’a do Shreka. Seryjność w kulturze popularnej, Wrocław 2011

Mittell J., Complex TV. The Poetics of Contemporary Television Storytelling, New York 2015

Mittell J., Narrative Complexity in Contemporary American Television. "The Velvet Light Trap: A Critical Journal of Film and Television", 2006, no. 58

Mittell J., Złożoność narracyjna we współczesnej telewizji amerykańskiej, tłum. D. Kuźma, [w:] Zmierzch telewizji? Przemiany medium. Antologia, red. T. Bielak, M. Filiciak, G. Ptaszek, Warszawa 2011

Newman M., From beats to arcs: Toward a poetics of television narrative, „The Velvet Light Trap: A Critical Journal of Film and Television", 2006, nr 58

Thompson K., Storytelling in Film and Television, Cambridge 2003

Thompson R., Television's Second Golden Age: From Hill Street Blues to ER, New York 1997

[36] Dla przykładu recenzje i wysokie noty przyznane serialowi na portalach: „Serialowa”, „Świat seriali”, „Na ekranie”. 